\section{HELP DEFEAT}

\section{MDS AND BLOOD}

\section{CANCER}

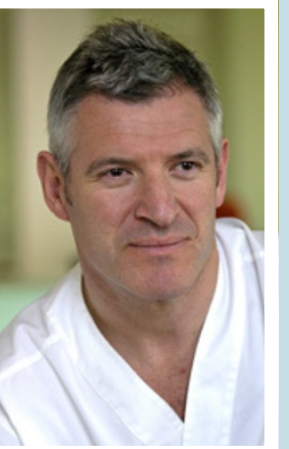

Leading dental technician Luke Barnett is calling on those in the dental field to support his campaign to help defeat MDS (Myelodysplastic syndrome) and blood cancer.

Luke's twenty year old niece Alice has MDS, a blood disorder which can lead to acute myelogenous leukemia and is writing a frank, funny and heartfelt blog about facing the condition and all that it entails. Her inspiring blog can be found at www.alicebyron.com

Luke said, 'I am devastated for my niece and no-one at the age of 20 with their entire life in front of them should have to face this kind of condition. That is why I am asking all those who can to take just a couple of minutes and sign up to become a donor so that we can beat MDS and all blood cancers.

'All that you need to do is to run a swab around your cheek and then send back in the envelope provided - and that's it! Surely we can all take two minutes out of our busy lives to do this? The more people who are on the registers, means more chance of finding a match. The odds are that you will never be called upon, but if you are then you alone will have the opportunity to give someone else a second chance of life by donating some of your blood stem cells.

For those lucky enough to be under 30, please visit www.anthonynolan.org/ apply-join-bone-marrow-register and if you are aged 30-55 please visit www. deletebloodcancer.org.uk/en/register-now

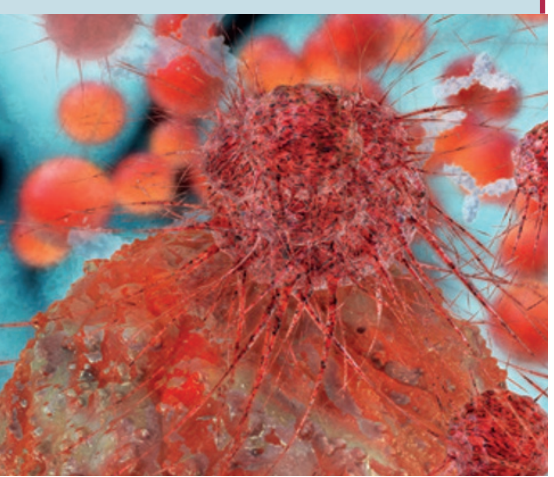

\title{
Introducing the new reader panel
}

BDJ Team is delighted to bring you a new reader panel for 2016. The constant evolution of the workforce allied with the changing needs of the population means that now more than ever the entire dental team is critical.

\section{Every month you can read an article from each member of} the reader panel on their chosen subject. Encompassing a wide variety of topics, experience and knowhow, the panel will aim to provide thought-provoking articles that will improve your team.

Without further ado, lets meet the new team!

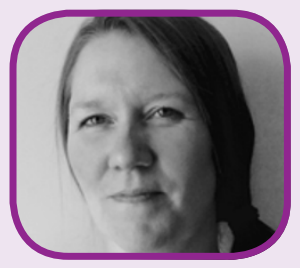

Nicola Sherlock

Special Care Dental Nurse

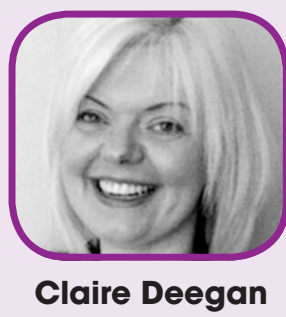

RDN

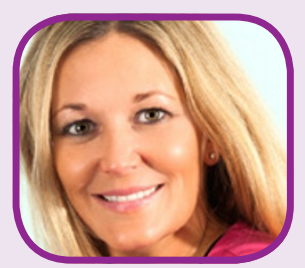

Nicole Sturzenbaum Principal Dentist

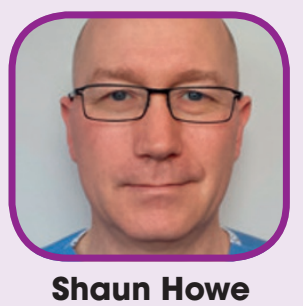

RDN

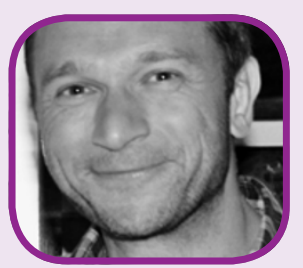

Ben Underwood

Dentist/App Developer/NHS Innovation Accelerator Fellow

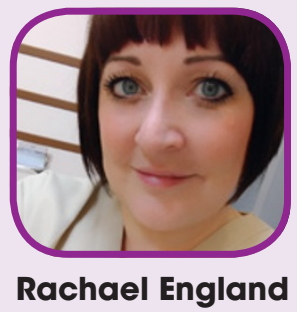

Dental Hygienist

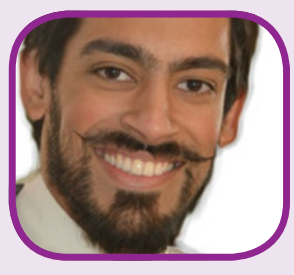

Shiraz Khan Dentist

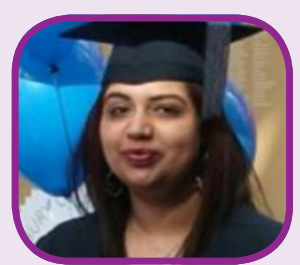

Asma Chaudhri Practice manager/RDN

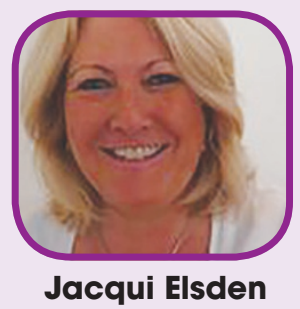

Dental Education Facilitator

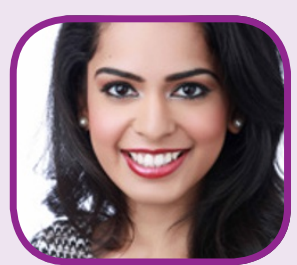

Reena Wadia

Specialty registrar In Periodontology, Associate Dentist and Clinical Tutor 